\title{
Fabrication and Significant Photoelectrochemical Activity of Titania Nanotubes Modified with Thin Indium Tin Oxide Film
}

\author{
Katarzyna Siuzdak $^{1} \cdot$ Mariusz Szkoda $^{2} \cdot$ Jakub Karczewski $^{3} \cdot$ Jacek Ryl $^{4} \cdot$ Kazimierz Darowicki $^{4}$. \\ Katarzyna Grochowska ${ }^{1}$
}

Received: 18 July 2017/Revised: 25 August 2017/Published online: 19 September 2017

(c) The Chinese Society for Metals and Springer-Verlag GmbH Germany 2017

\begin{abstract}
Ordered titanium dioxide nanotubes $\left(\mathrm{TiO}_{2} \mathrm{NTs}\right)$ modified with indium tin oxide (ITO) films were obtained via magnetron sputtering, in which ITO plate was used as a target, onto the as-anodized titania support followed by the calcination process. The morphology of fabricated material with deposited oxide was investigated using scanning electron microscopy. Raman and UV-Vis spectroscopies were utilized to characterize crystalline phase and optical properties of prepared samples, whereas X-ray photoelectron spectroscopy allowed determining the binding energy of present elements. In the case of titanium, three various oxidation states were identified and also the presence of indium and tin was confirmed. The electrochemical test carried out when the sample was exposed to light allows for selection of the most photoactive material. The highest photocurrent was registered when only 5-nm ITO layer was sputtered, and it equals 256 and $133 \mu \mathrm{A} \mathrm{cm} \mathrm{cm}^{-2}$ for the electrode material immersed in $0.5 \mathrm{M} \mathrm{KOH}$ and $\mathrm{K}_{2} \mathrm{SO}_{4}$ electrolytes, respectively, that is accordingly 3.5 and 4.4 times higher than the one observed for pristine titania. Furthermore, ITO-modified titania exhibits excellent photostability upon prolonged illumination that is of key importance for possible application in light-driven processes.
\end{abstract}

KEY WORDS: Titania nanotubes; Indium tin oxide; Photoactivity; Anodization; Magnetron sputtering; Electrochemical activity

Available online at http://link.springer.com/journal/40195

Katarzyna Siuzdak

ksiuzdak@imp.gda.pl

1 Centre for Plasma and Laser Engineering, The Szewalski Institute of Fluid-Flow Machinery, Polish Academy of Sciences, Fiszera 14, 80-231 Gdańsk, Poland

2 Department of Chemistry and Technology of Functional Materials, Chemical Faculty, Gdańsk University of Technology, Narutowicza 11/12, 80-233 Gdańsk, Poland

3 Faculty of Applied Physics and Mathematics, Gdansk University of Technology, Narutowicza 11/12, 80-233 Gdańsk, Poland

4 Department of Electrochemistry, Corrosion and Materials Engineering, Gdańsk University of Technology, Narutowicza 11/12, 80-233 Gdańsk, Poland

\section{Introduction}

Titanium dioxide in a form of one-dimensional nanotube has attracted extensive attention as a promising material with potential application in photodegradation of different organic contaminations, hydrogen production as well as in third generation of solar cells [1]. However, the photoactivity of $\mathrm{TiO}_{2}$ is limited to UV illumination due to its wide bandgap that significantly narrows widespread exploitation with the use of natural light source. In order to overcome this problem, many efforts were undertaken to shift activity towards visible waverange [2, 3]. Most popular approaches cover non-metal and metal doping, sensibilization with dye molecules, decoration with plasmonic nanoparticles $[4,5]$ as well as elaboration of sophisticated morphology [6] or 
formation of heterojunctions where titania acts as inorganic part and conducting polymer serves as organic part. Among those, nitrogen [7, 8], iodine [9], boron [10] and carbon [1] as well as phosphorus [11] are regarded as the most promising non-metal ones, whereas gold, iron, nickel and copper [12-14] are most frequently applied dopant metal atoms, resulting in the enhanced titania photoactivity and photostability comparing to the pristine material. Some reports suggest that the presence of oxides species other than titania on the external surface of $\mathrm{TiO}_{2}$ nanostructure can lead to better visible light photoactivity [15, 16]. Following that, many titania-based heterostructures were fabricated via deposition of iron, copper, nickel or cobalt oxides that result in composite material exhibiting enhanced photocatalitic activity towards 2-naphthol [17], improved photoconversion efficiency of dye-sensitized solar cell [18] or higher effectively as battery cathode [19] in comparison with unmodified titania. According to the recent reports, indium- or tin-doped $\mathrm{TiO}_{2}$ as well as $\mathrm{SnO}_{2} /$ $\mathrm{TiO}_{2}$ or $\mathrm{In}_{2} \mathrm{O}_{3} / \mathrm{TiO}_{2}$ heterostructures have drawn considerable attention due to wide range of potential applications and promising photoactivity. Titania modified by Sn was fabricated using typical wet chemistry methods (e.g. solgel, hydrothermal flow synthesis [20]) with the use of different dopant sources, such as $\mathrm{SnCl}_{4} \cdot 5 \mathrm{H}_{2} \mathrm{O}$ [21], $\mathrm{Sn}(\mathrm{Ot}-$ $\mathrm{Bu})_{4}$ [22] or $\left(\mathrm{NH}_{4}\right)_{2} \mathrm{SnF}_{6}$ [23]. It is also possible to use other methods such as pulsed ion implantation [24] or electrodeposition [25]. Similar approaches were proposed in the case of indium-doped titania, but as the dopant precursors $\mathrm{InCl}_{3}$ [26], $\mathrm{InNO}_{3} \cdot \mathrm{xH}_{2} \mathrm{O}$ [27] or pure indium metal plate as a target for thin layer e-beam evaporation [28] were used. In the case of indium-doped titania or $\mathrm{TiO}_{2}$ covered with indium oxides, unprecedented photocatalytic hydrogen production without using any co-catalyst, facilitated charge transport [26] and enhanced photoresponsivity [28] was observed. On the other hand, doping of titanium dioxide with tin ions or modification of its surface with tin oxide allows reaching much higher photocatalytic activity [29] and photoelectrochemical conversion [30, 31] comparing to unmodified titania. According to Li et al. [21], the enhanced photocatalytic activity results from more efficient photoinduced charge separation and visible light utilization by introducing the oxygen vacancies. Therefore, application of indium or tin ions during doping approach or their oxides in the case of surface modification could be regarded as a promising alternative for titanium dioxide modification with metal ions or nanoparticles that also significantly enhance photoactivity.

Nevertheless, to the best of our knowledge up to now, deposition of both tin and indium oxides mixture onto the surface of titania nanotubes was not realized although the combination of $\mathrm{Sn}$ and In oxide is worldwide known as a semitransparent, highly conductive layer. Furthermore, most of proposed methods are based on wet chemistry synthesis, where the main product is often contaminated, and in order to utilize the material in the form of layer, appropriate deposition techniques should be optimized. In this work, titania nanotubes were modified by indium tin oxide deposited onto as-anodized titanium plate. The modification was realized via magnetron sputtering using ITO target as a source of indium and tin atoms. The thickness of deposited ITO varies from 2.5 to $10 \mathrm{~nm}$ and was precisely controlled by quartz microbalance. Scanning electron microscopy combined with energy-dispersive spectroscopy was used to examine the morphology and the composition of prepared samples. The Raman and UV-Vis spectroscopies were utilized in order to confirm crystalline phase and absorbance ability, respectively. The chemical nature of elements was investigated using X-ray photoelectron spectroscopy, and the oxidation state of each atom present in the sample was carefully analysed. The photoactivity was tested by means of cyclic voltammetry and chronoamperometry measurements performed under electrode illumination when it was immersed both in neutral and alkaline electrolytes. Our study showed that simple magnetron sputtering with the use of ITO target and the layer of ordered $\mathrm{TiO}_{2}$ nanotubes as a substrate resulted in successful modification of titanium dioxide surface and highly enhanced titania photoactivity. Furthermore, the proposed procedure could be easily used for a large-scale production since both anodization and magnetron sputtering are applied on the industrial scale.

\section{Experimental}

\subsection{Sample Preparation}

Highly ordered $\mathrm{TiO}_{2} \mathrm{NTs}$ were prepared via two-step anodization according to the previously optimized procedure [7]. Before anodization, the substrate sample (Ti plate, Strem, 99.7\%) was ultrasonically cleaned in the following order: in acetone, ethanol and water for $10 \mathrm{~min}$ in each solvent, and ultimately dried in air. The process was realized in a two-electrode configuration at room temperature, where the titanium plate served as an anode and the platinum mesh as a cathode with a fixed distance of $2 \mathrm{~cm}$ between them. The first anodization took place in the electrolyte containing ethylene glycol (EG), 0.27 $\mathrm{M} \mathrm{NH}_{4} \mathrm{~F}$ and 1 vol.\% of deionized water. Anodization was performed at $40 \mathrm{~V}$ for $2 \mathrm{~h}$, with the initial voltage rate of $0.1 \mathrm{~V} / \mathrm{s}$. Then, the titanium plate was immersed in $0.5 \mathrm{wt} \%$ solution of oxalic acid for $12 \mathrm{~h}$ in order to remove the rugged nanotube layer. The second anodization process was performed on the as-cleaned titanium plate under the same conditions as those during the first anodization. In 
order to remove surface debris, the titanium plates covered with nanotubes were immersed in $0.05 \mathrm{wt} \% \mathrm{HF}$ for $180 \mathrm{~s}$. After the second anodization, the samples were rinsed with deionized water and then dried in air. Afterwards, Ti plates with tubular layers served as a support for ITO deposition using magnetron sputter coater (Quorum Tech, Q150S). The ITO thickness was controlled by quartz microbalance and equals 2.5, 5, 7.5 and $10 \mathrm{~nm}$. According to the deposited ITO thickness, the samples were labelled as $\mathrm{TiO}_{2}-\mathrm{ITO}-X$, where $X$ is assigned to the thickness value. Optimization of thickness of ITO layer concerned much thicker layers, but the highest activity was observed for films below $10 \mathrm{~nm}$ and thus presented results were limited to the range of $2.5-10 \mathrm{~nm}$. Finally, all samples were thermally treated at $450{ }^{\circ} \mathrm{C}$ for $2 \mathrm{~h}$, with a heating rate of $2{ }^{\circ} \mathrm{C} / \mathrm{min}$ allowing to reach target calcination temperature. Thermal processing enabled transformation from the amorphous into a crystalline phase of titania.

\subsection{Morphology and Structure Characterizations}

The surface morphology was observed using the Schottky field emission scanning electron microscopy (FEI Quanta FEG 250) with an ET secondary electron detector. Energydispersive X-ray spectra (EDX) analysis was performed using the EDX Spectrometer APEX 2i (Genesis). Escalab 250Xi by ThermoFisher Scientific was used to carry out high-resolution X-ray photoelectron spectroscopy (XPS) measurements to determine the chemical binding properties of the surface, utilizing monochromatic Al $K \alpha$ source with charge neutralization implemented by means of a flood gun. High-resolution spectra were recorded at energy step size of $0.1 \mathrm{eV}$ at pass energy of $10 \mathrm{eV}$. In order to normalize spectroscopic measurements, $X$ axis (binding energy, $\left.E_{\text {bin }}\right)$ from XPS spectrum was calibrated for peak characteristics of neutral carbon $1 s\left(E_{\text {bin }}=284.6 \mathrm{eV}\right)$. Data analysis was performed using the Avantage software provided by the manufacturer.

The UV-Vis reflectance spectra of titania nanotubes were measured with a dual-beam UV-Vis spectrophotometer (Lambda 35, Perkin-Elmer) equipped with a diffuse reflectance accessory. The spectra were registered in a range of $350-700 \mathrm{~nm}$, with a scanning speed of $120 \mathrm{~nm} /$ min. The bandgap energy was determined according to Tauc/Davis model [32] where for crystalline material the following formula is applied: $(\alpha)^{n}=A\left(E_{\mathrm{ph}}-E_{\mathrm{g}}\right) . E_{\mathrm{g}}$ is the optical bandgap, $E_{\mathrm{ph}}$ is photon energy, $\alpha$ stays for absorption coefficient, whereas $A$ is a constant and $n$ is an index characterizing the type of optical transition. Since anatase $\mathrm{TiO}_{2}$ is indirect bandgap semiconductor, $n$ equals 0.5 .

The Raman spectra were recorded by a confocal microRaman spectrometer (InVia, Renishaw) with sample excitation at $514 \mathrm{~nm}$ by means of an argon ion laser operating at $5 \%$ of its overall power $(50 \mathrm{~mW})$.

The phase composition was determined by X-ray diffraction technique (XRD) using the Philips X'Pert Pro MPD using $\mathrm{Cu} K \alpha \quad(1.5406 \AA)$ radiation at room temperature.

\subsection{Electrochemical and Photoelectrochemical Measurements}

Electrochemical measurements were carried out using an Autolab PGStAT302 N potentiostat-galvanostat system (Methrom, Autolab) in a standard three-electrode assembly, where titanium foil covered by nanotubes served as a working electrode (active surface area of $0.3 \mathrm{~cm}^{2}$ ). Electrodes were tested in contact with deaerated aqueous $0.5 \mathrm{M}$ $\mathrm{K}_{2} \mathrm{SO}_{4}$ or $0.5 \mathrm{M} \mathrm{KOH}$ electrolyte. An electrochemical cell was equipped with a quartz window enabling electrode material illumination. The photoactive layers were irradiated by the $150 \mathrm{~W}$ Xenon lamp (Osram XBO 150) equipped with an AM 1.5 filter allowing to obtain simulated solar light and the automated light chopper with a period set on $90 \mathrm{~s}$ enabling transient photocurrent measurements. The irradiance of incident light was calibrated to $100 \mathrm{~mW} / \mathrm{cm}^{2}$ using a reference cell ( $\mathrm{Si}$ solar cell, Rera). The photocurrent measurements were carried out at $+0.5 \mathrm{~V}$ versus $\mathrm{Ag} / \mathrm{AgCl} / 0.1 \mathrm{M} \mathrm{KCl}$ bias voltage.

The electrochemical impedance spectra for pure titania and titania modified with 5- and 7.5-nm ITO were registered for working electrode at its resting potential. The frequency range covers $20-0.1 \mathrm{~Hz}$, whereas the amplitude of the AC signal equals $10 \mathrm{mV}$.

\section{Results and Discussion}

\subsection{Morphology and Structure Studies}

The morphology and cross-section images of the obtained titania samples are shown in Fig. 1. The pristine titania layer (see Fig. 1a) is characterized by well-ordered nanotubes with the internal diameter of $70 \mathrm{~nm}$ and the wall thickness of $25 \mathrm{~nm}$. The length of $\mathrm{TiO}_{2} \mathrm{NT}$ is determined to be $2.2 \mu \mathrm{m}$ (Fig. 1b). When the 5- or 10-nm ITO layer is deposited, the surface morphology changes and outer edges of tubes are overgrown by crystallites (Fig. 1c, d). Generally, in the case of modified titania the tube interior is not filled which enables efficient electrolyte penetration inside the material. However, in the case of $\mathrm{TiO}_{2}-\mathrm{ITO}-10$ sample, larger agglomeration of crystallites could be observed, resulting in partial coverage of the empty space inside the $\mathrm{TiO}_{2}$ nanotubes that limits the infiltration of electrolyte within the material. In order to preserve the surface 

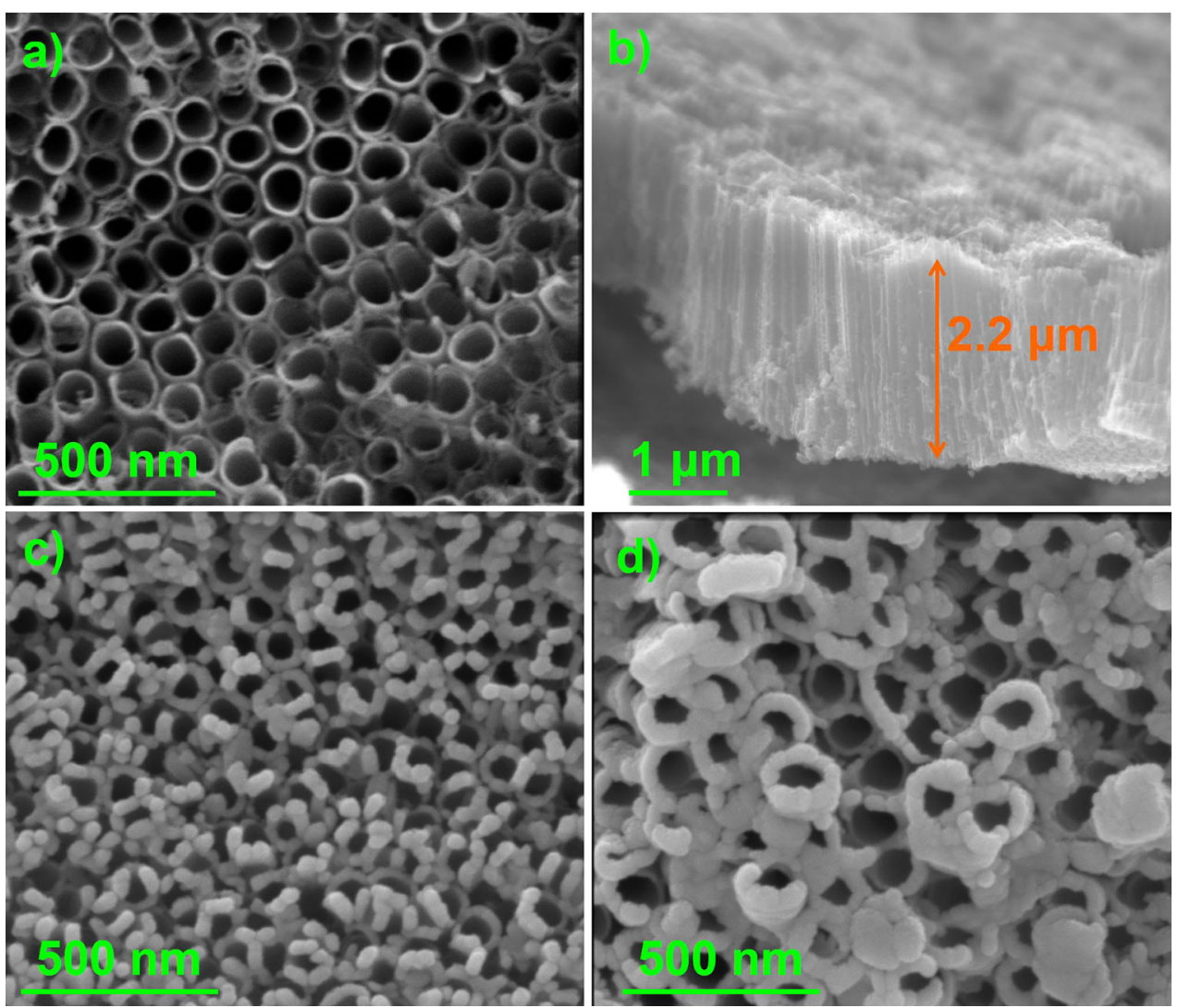

Fig. 1 SEM images of a pristine $\mathrm{TiO}_{2} \mathrm{NT}$ s surface, $\mathbf{b}$ its cross-section, $\mathbf{c} \mathrm{TiO}_{2} \mathrm{NT}-\mathrm{ITO}-5$, $\mathbf{d} \mathrm{TiO}_{2}-\mathrm{ITO}-10$

morphology typical for ordered titania nanotubes, ITO layers thicker than $10 \mathrm{~nm}$ should be avoided.

The Raman spectra for pristine and modified $\mathrm{TiO}_{2} \mathrm{NTs}$ are given in Fig. 2. The Raman signals characteristic for anatase crystalline phase is observed at 144, 196, 396, 516 and $634 \mathrm{~cm}^{-1}$ and is assigned for respective active modes: $\mathrm{E}_{\mathrm{g}(1)}, \mathrm{E}_{\mathrm{g}(2)}, \mathrm{B}_{1 \mathrm{~g}}, \mathrm{~A}_{1 \mathrm{~g}}$ and $\mathrm{E}_{\mathrm{g} 3}$. In the case of modified samples, it could be noticed that the intensity of all bands decreases with the increase in deposited ITO thickness. This may be caused by the ITO cover formed at the titania

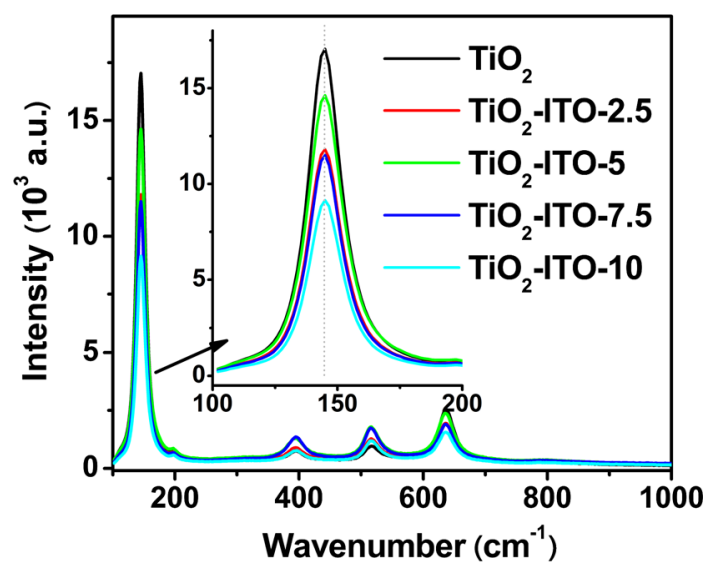

Fig. 2 Raman spectra of pristine and ITO-modified titania nanotubes surface that could inhibit the crystallization rate [33]. However, as shown in the enlarged view of $\mathrm{E}_{\mathrm{g}(1)}$ mode presented as an inset in Fig. 2, no shift can be observed before and after ITO deposition within the detect resolution of the apparatus [34]. Thus, the modification by ITO does not affect the crystal structure and any expansion of the unit cell volume may not occur. The similar Raman spectra for both pristine and tin-doped titania were registered by $\mathrm{Li}$ et al. [21] and Yan et al. [27]. It should be also noted that due to the small amount of indium, no signals typical for In-O modes were observed as it was reported by Wang et al. [35].

Additionally, to confirm the crystalline phase the XRD spectra for all the samples were also registered. As it could be observed in Fig. 3, the signals typical for anatase and the titanium substrate could be distinguished [36]. However, any peak characteristic for ITO does not emerge clearly from the background that is probably caused by too little amount of deposited material onto the titania support. Summarizing, both Raman and XRD spectra are consistent.

\subsection{Optical Properties}

The UV-Vis absorption spectra of $\mathrm{TiO}_{2}$ and various $\mathrm{TiO}_{2}$ ITO samples are shown in Fig. 4. For all investigated 


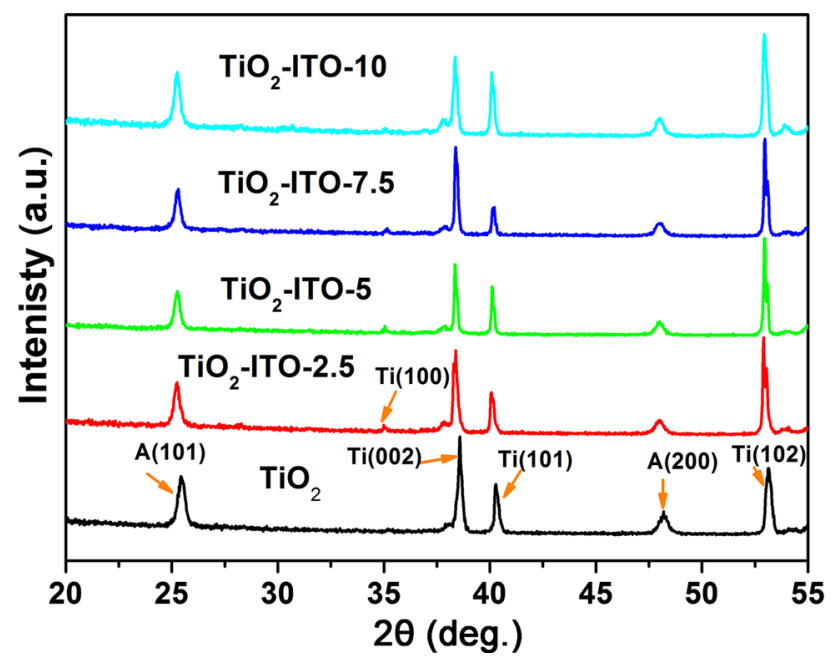

Fig. 3 XRD spectra registered for pristine and ITO-modified titania nanotubes

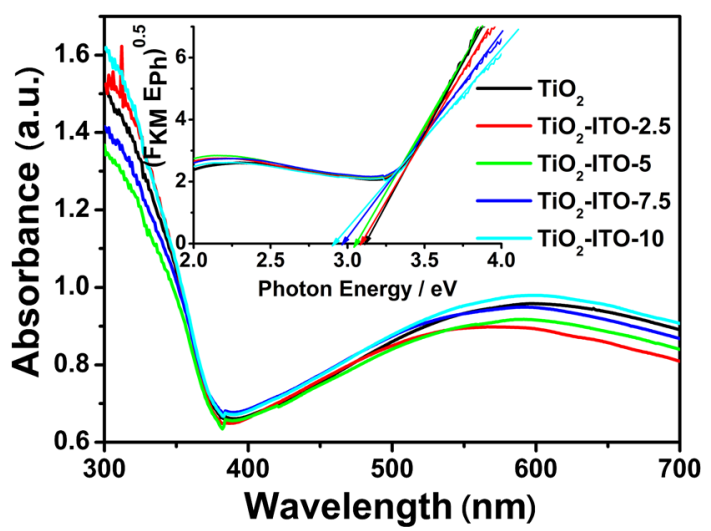

Fig. 4 Absorbance spectra and the transformation of Kubelka-Munk plot versus photon energy of obtained samples (inset)

materials, two absorption bands are observed. The first one in UV region results from the wide bandgap energy of titania, while the second one in the visible range with maximum ca. $600 \mathrm{~nm}$ is attributed to sub-bandgap states originating from the specific tubular titania structure [7, 37]. As an inset in Fig. 4, the Tauc plot is given. The intrinsic bandgaps $\left(E_{\mathrm{bg}}\right)$ of pure and modified $\mathrm{TiO}_{2}$ were determined by drawing the tangent lines and reading the intercept on the photon energy axis. The energy bandgap for unmodified titania equals $3.12 \mathrm{eV}$, whereas for modified materials the value of $E_{\mathrm{bg}}$ is lower and reaches 3.09, 3.06, 2.98 and $2.92 \mathrm{eV}$ for $\mathrm{TiO}_{2}-\mathrm{ITO}-2.5, \mathrm{TiO}_{2}-\mathrm{ITO}-5$, $\mathrm{TiO}_{2}-\mathrm{ITO}-7.5$ and $\mathrm{TiO}_{2}-\mathrm{ITO}-10$, respectively. This red shift could result from surface modification of titania. Although the highest difference between $E_{\mathrm{bg}}$ for $\mathrm{TiO}_{2}$ and $\mathrm{TiO}_{2}-\mathrm{ITO}-10$ equals only $0.2 \mathrm{eV}$, it could be expected that ITO-modified materials would be more sensitive to the solar light than pristine titania and the photoactivity could be enhanced.

\subsection{Material Composition}

In order to investigate the chemical nature of elements present in the prepared samples, the X-ray photoelectron spectroscopy was utilized. In Fig. 5, the XPS survey spectrum collected for $\mathrm{TiO}_{2}-\mathrm{ITO}-5$ sample is given proving the presence of indium, tin, titanium, oxygen and carbon in the material. For detailed investigations, the XPS spectra were registered in the binding energy region typical for all elements and are shown in Fig. 6. For the comparison, the data obtained for pure titania are used as a reference and have already shown and discussed carefully in our previous reports $[9,10]$.

Both signals typical for indium (Fig. 6a) and tin (Fig. 6b) were clearly observed that confirm their presence at the $\mathrm{TiO}_{2}$ surface. For In as well as for $\mathrm{Sn}$, a strong doublet peak was found and assigned, respectively, to $d_{5 / 2}$ and $d_{3 / 2}$ orbitals. The position of $\operatorname{In} 3 d_{5 / 2}$ maximum $(445.4 \mathrm{eV})$ is similar to the one registered for $\operatorname{In}_{2} \mathrm{O}_{3}$ as well as for indium-doped titania [35]. It suggests that indium is present in the form of $\mathrm{In}^{3+}$ species [38]. It should be also noted that localization of In $3 d_{5 / 2}$ is similar to indium present in ITO sample as shown by Thogersen et al. [39]. Thus, we postulate that the chemical environment typical for indium tin oxide could be also found at the titania surface [40]. It should be noted that it is hard to distinguish between metallic In and $\operatorname{In}_{2} \mathrm{O}_{3}$ because the energy difference is only $0.2 \mathrm{eV}$. Additionally, the satellite peak for metallic state does not appear at low concentration and in the case of titania support it is overlapped by the titanium oxide species. Nevertheless, most likely indium could be linked to oxygen that is provided by the titania lattice.

In the case of tin, $d_{5 / 2}$ and $d_{3 / 2}$ signals are located at 487.1 and $495.6 \mathrm{eV}$, respectively, with a split equal to $8.5 \mathrm{eV}$. They may be attributed to the substitutional $\mathrm{Sn}^{4+}$ since the position of $\mathrm{Sn} 3 d_{5 / 2}$ and the split value are similar to those reported for stoichiometric tin oxide (IV). Any signal providing the metallic state of tin was not recorded.

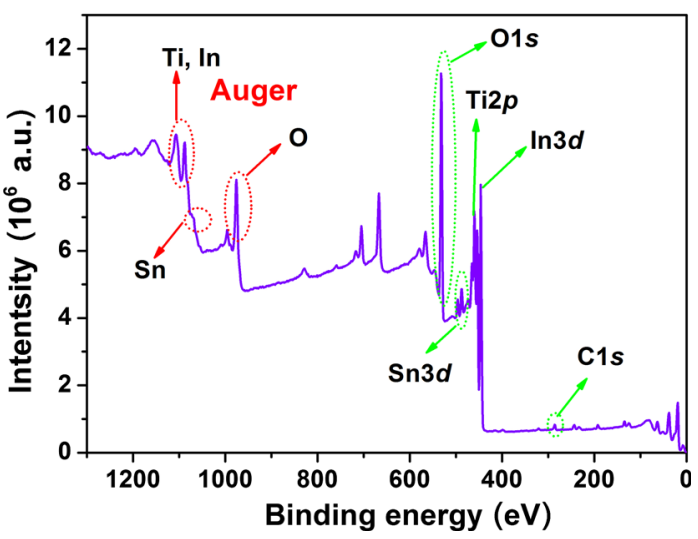

Fig. 5 XPS survey spectrum registered for $\mathrm{TiO}_{2}-\mathrm{ITO}-5$ 

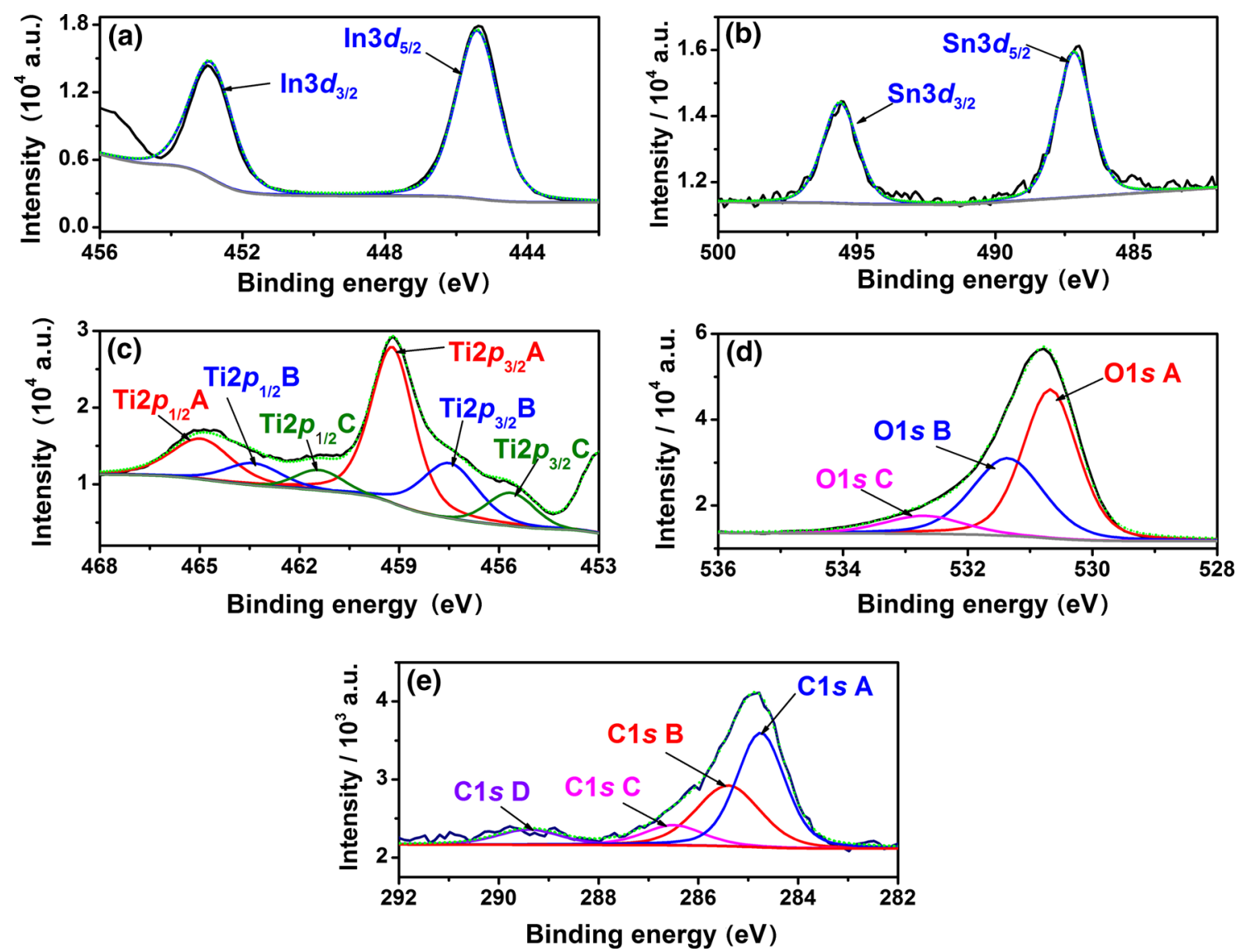

Fig. 6 High-resolution XPS spectra recorded at: a indium, b tin, $\mathbf{c}$ titanium, $\mathbf{d}$ oxygen, e carbon binding energy region of TiO ${ }_{2}-\mathrm{ITO}-5$

According to Zatsepin et al. [24], the isovalent incorporation of tin could take place and tin (IV) may be introduced instead of $\mathrm{Ti}^{4+}$ in the titania crystal lattice. Following Donley et al. [40], $d_{5 / 2}$ located at such high binding energy value $(>487.1 \mathrm{eV})$ may be assigned to $\mathrm{SnOH}$-like species.

The spectrum registered for titanium of ITO sample presented in Fig. 6c is of different shape that one typical for pristine $\mathrm{TiO}_{2} \mathrm{NT}$ as we previously reported [10]. On the contrary to pure titania, the fitting procedure requires three doublets with $2 p_{3 / 2}$ maxima located at 459.2, 457.6 and $455.7 \mathrm{eV}$ for A-, B- and C-labelled peaks, respectively. The signal marked as $\mathrm{Ti} 2 p_{3 / 2} \mathrm{~A}$ is attributed to $\mathrm{Ti}^{4+}$ oxidation state in anatase crystal [41], whereas $\mathrm{Ti} 2 p_{3 / 2} \mathrm{~B}$ peak could be assigned to $\mathrm{Ti}^{3+}$ fraction. The peak $\mathrm{A}$ shows a 0.4-eV shift towards higher energy values comparing to the spectra for pure $\mathrm{TiO}_{2}$ which are likely attributed to the interaction between titanium, oxygen and tin species [22].The smallest peak $\mathrm{C}$ results from the presence of titanium characterized with $2+$ oxidation state [42]. The presence of titania with $3+$ and $2+$ oxidation states confirms non-stoichiometric titanium oxide formation. Because ITO layer was deposited onto the as-anodized titania and then calcination process was carried out, the ITO film could be regarded as a barrier for oxygen diffusion from the ambient atmosphere to the titania layer during heat treatment process. As a result, formation of stoichiometric $\mathrm{TiO}_{2}$ was hampered. Additionally, tin and indium could be introduced at the surface region instead of oxygen in the crystal lattice, reducing the oxygen content in the nearest vicinity of titanium atoms.

In Fig. 6d, the spectrum registered for oxygen is shown. Three singlets were sufficient for proper fitting result. The highest one is attributed to $\mathrm{O}-\mathrm{Ti}$ [43], while the second may correspond to oxygen in $\mathrm{SnO}_{2}$ [22]. As it was mentioned by Duan et al. [22], the binding energy of lattice oxygen located in between $\mathrm{TiO}_{2}$ and $\mathrm{SnO}_{2}$ may origin from the variation of electronegativity of both metals: Ti and $\mathrm{Sn}$. The smallest one $\mathrm{O} 1 s \mathrm{C}$ could be attributed to the surface hydroxyl groups: HO-Ti [44], $\mathrm{HO}-\mathrm{Sn}$ [45] and $\operatorname{In}(\mathrm{OH})_{x}$ [39]. It should be also noted that $\mathrm{O} 1 \mathrm{sB}$ and $\mathrm{O} 1 \mathrm{sC}$ locations are also typical for $\mathrm{C}-\mathrm{O}$ and $\mathrm{C}=\mathrm{O}$ arrangements, respectively.

The XPS analysis performed in the energy region characteristic for carbon exhibits four singlets. The most intense $\mathrm{C} 1 s \mathrm{~A}(284.8 \mathrm{eV})$ is attributed to $\mathrm{C}-\mathrm{C}$ bonds and is typical for contamination of the titania surface. Such carbon species are always found for titania nanotubes obtained via anodization performed in an organic electrolyte [46], 


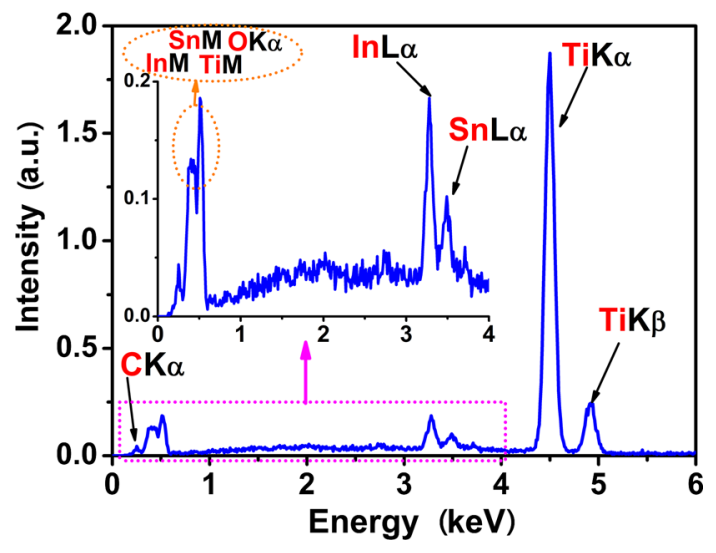

Fig. 7 EDX spectrum of $\mathrm{TiO}_{2}-\mathrm{ITO}-5$ sample

but also could be regarded as a contamination from the XPS instrument [47].

Next signal B $(285.4 \mathrm{eV})$ can be assigned to carbon linked to oxygen by a single bond [48], whereas peak C1sC $(286.5 \mathrm{eV})$ could be interpreted as a carbon bound to oxygen through double bond [49]. The $\mathrm{C} 1 s \mathrm{D}(289.4 \mathrm{eV})$ could be regarded as carboxylate species [50] or even attributed to the arrangement of $\mathrm{Ti}-\mathrm{O}-\mathrm{C}=\mathrm{O}$ [51].

Apart from XPS data, EDX spectrum (see Fig. 7) of $\mathrm{TiO}_{2}$-ITO-5 clearly confirms that apart from titanium, oxygen and carbon, also tin and indium are present. The calculated atomic contents of indium and tin are 2.84 and 0.45 at.\%, respectively.

\subsection{Electrochemical and Photoelectrochemical Activity}

In order to investigate electrochemical properties of obtained ITO-modified titania, first cyclic (CV) and linear (LV) voltammetry measurements were carried out. In Fig. 8, the $\mathrm{CV}$ curves registered in $0.5 \mathrm{M} \mathrm{K}_{2} \mathrm{SO}_{4}$ are shown. In general, the $\mathrm{CV}$ shape is similar for all materials and typical for n-type semiconductor. In the anodic part, a very small charging current is registered, whereas below $-0.5 \mathrm{~V}$ versus $\mathrm{Ag} / \mathrm{AgCl} / 0.1 \mathrm{M} \mathrm{KCl}$ the current increases. The greatest cathodic current was obtained for $\mathrm{TiO}_{2}-\mathrm{ITO}-$ 10 and may be related to the amount of deposited ITO. According to Senthilkumar et al. [52], it may result from the reduction of $\mathrm{Sn}^{4+}$ and $\mathrm{In}^{3+}$ to the lower oxidation states. However, the subsequent $\mathrm{CV}$ curves in shown potential range are repeatable and any material dissolution is not observed, confirming high material stability.

The linear voltammetry curves (see Fig. 9) measurements of the prepared electrode material were taken by using several intermittent cycles of white light illumination to evaluate the sensitivity of the samples to solar radiation, which is a key factor for the practical photoelectrochemical application. In the case of all examined samples with

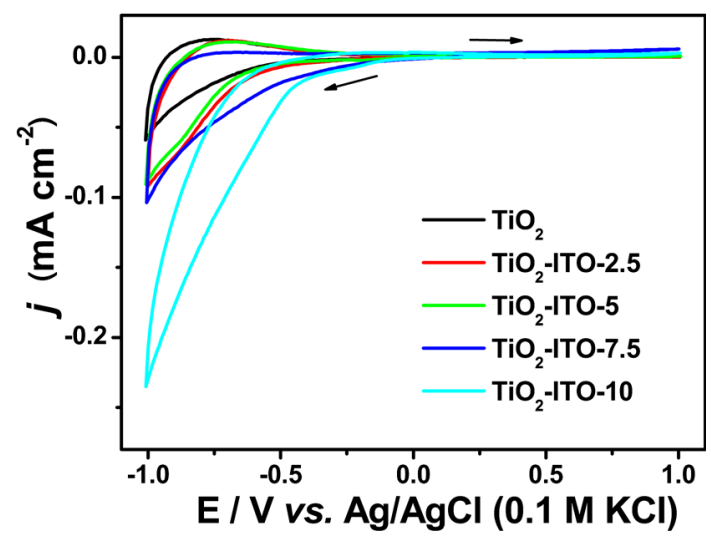

Fig. 8 Cyclic voltammetry curves of pristine titania and $\mathrm{TiO}_{2} \mathrm{NTs}$ modified with different ITO films (electrolyte $0.5 \mathrm{M} \mathrm{K}_{2} \mathrm{SO}_{4}$, $v=50 \mathrm{mV} / \mathrm{s}$ )

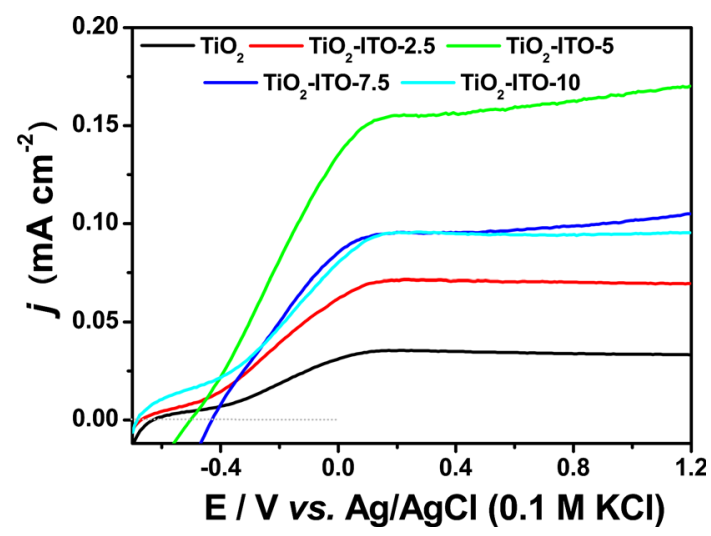

Fig. 9 Linear sweep voltammograms under different photoanodes: pristine $\mathrm{TiO}_{2} \mathrm{NTs}$ and ITO-modified $\mathrm{TiO}_{2} \mathrm{NTs}$ in $0.5 \mathrm{M} \mathrm{K}_{2} \mathrm{SO}_{4}$ $(v=10 \mathrm{mV} / \mathrm{s})$

increasing potential applied to the anode, the registered photocurrent gradually increases up to $+0.15 \mathrm{~V}$ where the plateau is reached. The saturated currents for all ITOmodified titania are obviously higher in comparison with that generated at the electrode of pristine titania nanotubes. It should be also noted that upon ITO deposition the onset potential $\left(E_{\text {on }}\right)$ of titania samples was changed, indicating that the energetics of the band edges were modified. In the case of two samples $\mathrm{TiO}_{2}-\mathrm{ITO}-5$ and $\mathrm{TiO}_{2}-\mathrm{ITO}-7.5, E_{\text {on }}$ is anodically shifted due to the possible increase in flat-band potential value. Therefore, 5- and 7.5-nm-thick sputtered ITO layer could decrease the charge transfer resistance across the photoanode-aqueous electrolyte interface. In order to verify this hypothesis, the electrochemical impedance spectra were registered and are shown in Fig. 10. As could be observed, the modification of titania led to a significant change in the overall material resistance. The $\mathrm{TiO}_{2}$-ITO-5 sample exhibits the lowest resistance that significantly affects its photoactivity (measured as a 


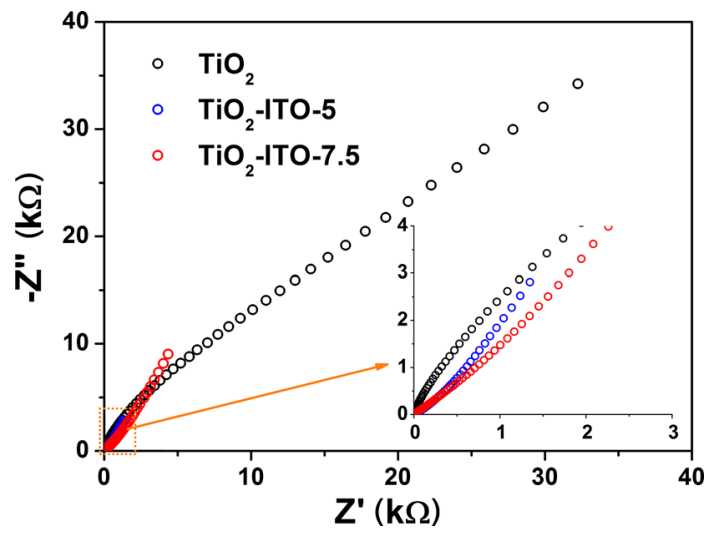

Fig. 10 Impedance spectra registered at the resting potential for pristine $\mathrm{TiO}_{2} \mathrm{NTs}$ and titania modified with 5 and $7.5 \mathrm{~nm}$ of ITO immersed in $0.5 \mathrm{M} \mathrm{K}_{2} \mathrm{SO}_{4}$

photocurrent) that is far superior to that observed for other materials.

The photostability measured at $+0.5 \mathrm{~V}$ bias voltage was verified in neutral $(\mathrm{pH}=7)$ and basic solution $(\mathrm{pH}=13)$, and both curves are presented in Fig. 11a, b, respectively. The anodic bias applied to the working electrode caused electron migration from the $\mathrm{TiO}_{2}$ layer towards the external circuit that could suppress electron and hole recombination [53]. The shape of CA curve shows the rapid current increase and decrease according to the light switch on/off stages. The values of photocurrent obtained after $300 \mathrm{~s}$ of chronoamperometry tests performed in different $\mathrm{pH}$ conditions are listed in Table 1. In basic solution, the values of registered photocurrent are ca. two times higher than those obtained in neutral electrolyte, which results from the surface reactions with the hydroxyl radicals that trap holes more efficiently than water molecules [54]. As it is shown, the photocurrent enhancement factor (EF) for all ITOmodified titania is above 2 comparing to pure $\mathrm{TiO}_{2} \mathrm{NTs}$, whereas the most photoactive sample is the one covered with $5 \mathrm{~nm}$ of ITO layer and EF reaches 4.4 or 3.5 when the
Table 1 Photocurrent values obtained for investigated electrode materials under UV-Vis illumination after $300 \mathrm{~s}$ of measurements in $0.5 \mathrm{M} \mathrm{K}_{2} \mathrm{SO}_{4}$ and $0.5 \mathrm{M} \mathrm{KOH}(E=+0.5 \mathrm{~V}$ vs. $\mathrm{Ag} / \mathrm{AgCl} / 0.1 \mathrm{M}$ $\mathrm{KCl})$

\begin{tabular}{lccccc}
\hline $0.5 \mathrm{M} \mathrm{K}_{2} \mathrm{SO}_{4}$ & & & & $0.5 \mathrm{M} \mathrm{KOH}$ & \\
\cline { 1 - 2 } & $J\left(\mu \mathrm{Acm}^{-2}\right)$ & EF & & $J\left(\mu \mathrm{Acm}^{-2}\right)$ & EF \\
\hline $\mathrm{TiO}_{2}$ & 30 & 1 & 73 & 1 \\
$\mathrm{TiO}_{2}-\mathrm{ITO}-2.5$ & 62 & 2.1 & 157 & 2.1 \\
$\mathrm{TiO}_{2}-\mathrm{ITO}-5$ & 133 & 4.4 & 256 & 3.5 \\
$\mathrm{TiO}_{2}-\mathrm{ITO}-7.5$ & 81 & 2.7 & 204 & 2.8 \\
$\mathrm{TiO}_{2}$ ITO-10 & 83 & 2.8 & 197 & 2.7 \\
\hline
\end{tabular}

sample is immersed in $0.5 \mathrm{M} \mathrm{K}_{2} \mathrm{SO}_{4}$ or $\mathrm{KOH}$ solution, respectively. It should be underlined that obtained enhancement is much higher than those of $\mathrm{Hu}$ et al. [55] for $\mathrm{SnO}_{2}$-modified $\mathrm{TiO}_{2} \mathrm{NTs}$ (EF $\approx 2$ in $0.5 \mathrm{M} \mathrm{KOH}$ ), $\mathrm{Su}$ et al. [55] for ITO sputtered on $\mathrm{TiO}_{2}(\mathrm{EF} \approx 1.3$ in $0.1 \mathrm{M}$ $\mathrm{NaClO}_{4}$ ), Sun et al. [56]. for tin-doped titania $(\mathrm{EF} \approx 1$.4in $1 \mathrm{M} \mathrm{KOH})$ or $\mathrm{Xu}$ et al. [30] for Sn-doped $\mathrm{TiO}_{2}(\mathrm{EF} \approx 2.5$ in $1 \mathrm{M} \mathrm{KOH})$. Since no research towards titania nanotubes modified by ITO has been reported yet, the comparison was made with other $\mathrm{TiO}_{2}$ nanostructures doped by tin or indium or their mixtures that were afterwards characterized as a photoanode material.

Furthermore, the verification of photostability of the most photoactive $\mathrm{TiO}_{2}-\mathrm{ITO}-5$ sample was carried out for $4 \mathrm{~h}$ of prolonged material irradiation and is depicted in Fig. 12. As it could be observed, although the sample was exposed to solar light in continuous mode, it does not lose its ability to efficiently generate photocurrent. Thus, titania modified by only $5 \mathrm{~nm}$ of indium tin oxide could be regarded as a promising photoelectrode since the fabrication method including anodization, calcination and finally quick ITO deposition via magnetron sputtering could be also easily scaled up.
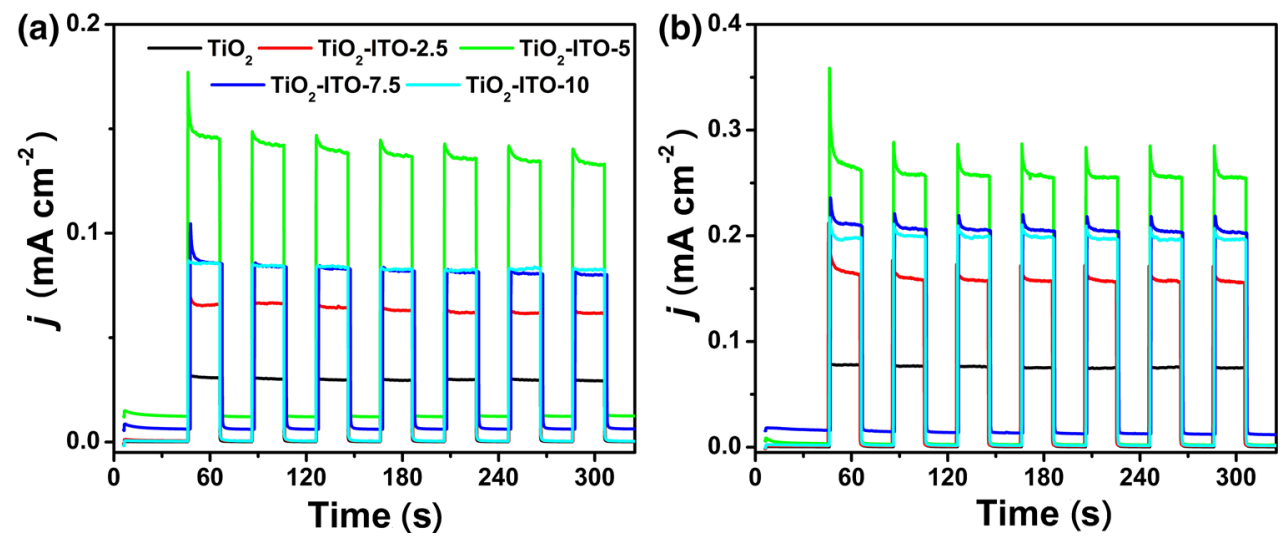

Fig. 11 Transient photocurrent responses of $\mathrm{TiO}_{2} \mathrm{NTs}$ with and without ITO coverage in a $0.5 \mathrm{M} \mathrm{K}_{2} \mathrm{SO}_{4}$ and $\mathbf{b} 0.5 \mathrm{M} \mathrm{KOH}(E=+0.5 \mathrm{~V}$ vs. $\mathrm{Ag} / \mathrm{AgCl} / 0.1 \mathrm{M} \mathrm{KCl})$ 


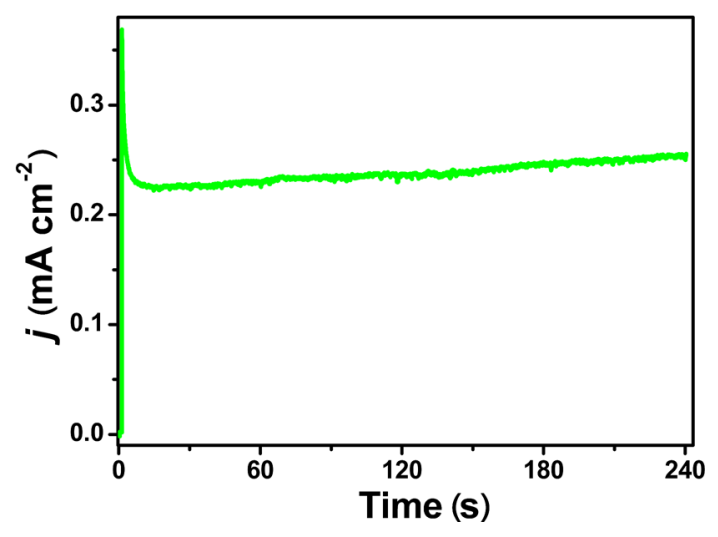

Fig. 12 Time-dependent photocurrent density of $\mathrm{TiO}_{2}-\mathrm{ITO}-5$ sample under continuous simulated sunlight illumination $(>4 \mathrm{~h})$ registered in $0.5 \mathrm{M} \mathrm{KOH}$ at $+0.5 \mathrm{~V}$ vs. $\mathrm{Ag} / \mathrm{AgCl} / 0.1 \mathrm{M} \mathrm{KCl}$

As it is usually justified, the enhancement of the photoactivity of the ITO-sputtered titania nanotubes could result from the decreased bandgap energy comparing to unmodified sample. However, as it was already shown, the difference in $E_{\mathrm{bg}}$ values for pure and modified titania is not significant and therefore the increase in photocurrent generation could result from other reasons. First, according to the XPS analysis, apart from $4+$ oxidation state that is typical for $\mathrm{TiO}_{2}, 3+$ and $2+$ oxidation states were also identified that could be related both to the limited access to oxygen because of the ITO barrier layer and to the incorporation of In and $\mathrm{Sn}$ in the surface region. Such surface doping may lead to the increase in oxygen vacancy [56] and formation of $\mathrm{Sn}-\mathrm{O}-\mathrm{Ti}$ and $\mathrm{In}-\mathrm{O}-\mathrm{Ti}$ bonds that may modify the electronic structure of titania. Following that, the density of the states near the conduction band minimum increases by mixing with the Sn and In oxide clusters and the absorption of light is enhanced. Furthermore, according to Amoli et al. [57] the size of metal oxide clusters located at the titania surface could be very small and in such case quantum size effects are more pronounced in the conduction band than the valence band for most of the semiconductors. Quantum confinement effect is then regarded as a driving force for the efficient charge transfer between the conduction bands within nanoscale heterojunctions: $\mathrm{TiO}_{2} /$ $\mathrm{In}_{2} \mathrm{O}_{3}$ and $\mathrm{TiO}_{2} / \mathrm{SnO}_{2}$.

The improved photoelectrochemical performance could be also explained in terms of junction formation at the contact surface of $\mathrm{TiO}_{2}, \mathrm{SnO}_{2}$ and $\mathrm{In}_{2} \mathrm{O}_{3}$ layers. Considering the triple-heterojunction case, the possible mechanism of the charge transfer within photoanode could be explained basing on the energy bands alignment (see Fig. 13). The energy bands of titania were localized in agreement with our previous report [58], whereas for $\mathrm{SnO}_{2}$ and $\operatorname{In}_{2} \mathrm{O}_{3}$ we utilized literature data $[59,60]$. Illumination of the photoanode leads to the $\mathrm{TiO}_{2}, \mathrm{SnO}_{2}$ and $\mathrm{In}_{2} \mathrm{O}_{3}$ photoexcitation. Taking into account the location of metal oxides conduction bands, one may expect transfer of the electrons from $\mathrm{In}_{2} \mathrm{O}_{3}$ to $\mathrm{TiO}_{2}$ and next $\mathrm{SnO}_{2}$, and then to the electron collector ( $\mathrm{Ti}$ foil). Thus, the range of the absorbed light, which can be then converted into chemical and electric energy, is extended due to the presence of $\mathrm{SnO}_{2}$ and $\mathrm{In}_{2} \mathrm{O}_{3}$ in comparison with pristine $\mathrm{TiO}_{2}$. Photoexcitation of semiconductors leads to holes formation within valence bands of the semiconductor. Holes can be directly utilized for water oxidation on the surface of materials. According to the band alignment, the hole transfer from the valence band of $\mathrm{SnO}_{2}$ to titania and then towards the valence band of $\operatorname{In}_{2} \mathrm{O}_{3}$ is possible. Thus, the formation of an inorganic-inorganic junction can also

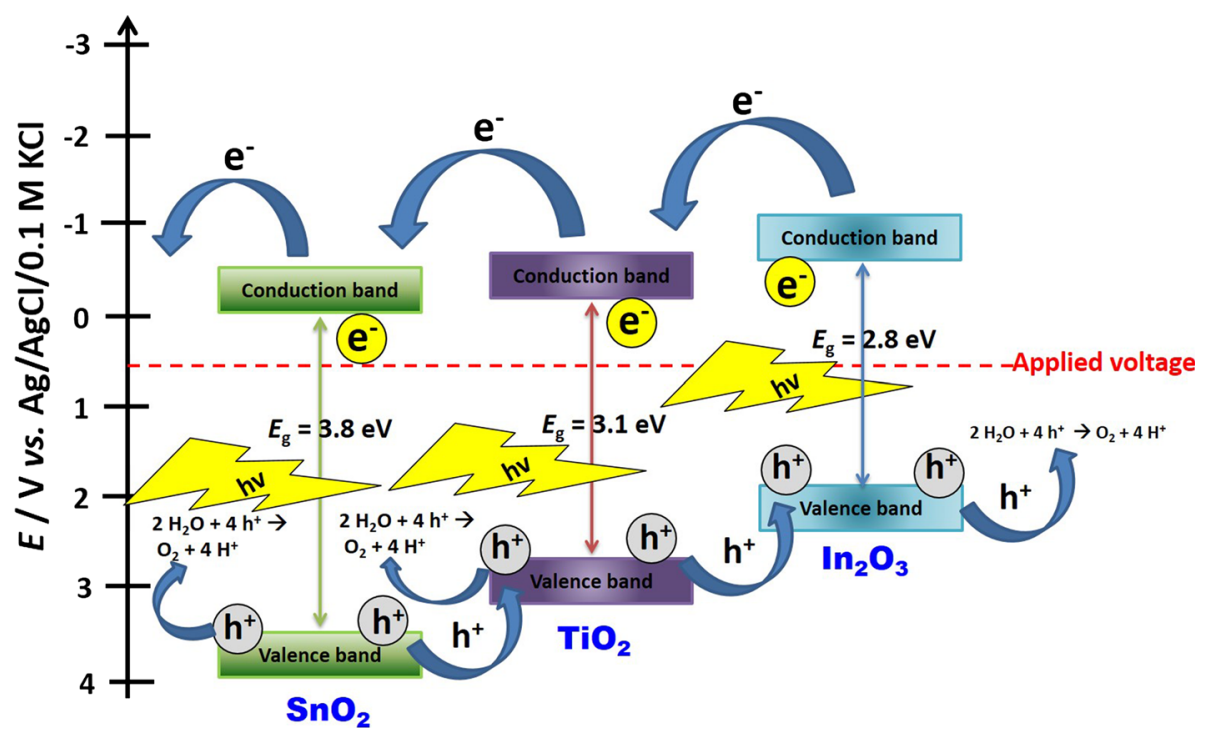

Fig. 13 Energy band scheme depicting the photoexcitation and charge transfer within the $\mathrm{SnO}_{2} / \mathrm{InO}_{3} / \mathrm{TiO}_{2}$ heterojunction 
positively affect the charge-carrier separation efficiency that inhibits electron/hole recombination and finally results in the photocurrent enhancement.

\section{Conclusion}

In summary, a composite material of highly ordered titania nanotubes covered with ITO layers has been fabricated by an anodization of titanium foil in fluoride ions containing bath, followed by magnetron sputtering of thin indium tin oxide films (up to $10 \mathrm{~nm}$ ) and finally thermal treatment at $450{ }^{\circ} \mathrm{C}$. The series of obtained samples were recognized as anatase, and their bandgap energy values decrease in accordance with increasing ITO coverage. As it was verified by X-ray photoelectron spectroscopy, tin and indium possess $4+$ and $3+$ oxidation states, respectively, whereas titanium exhibits multioxidation states $(2+, 3+$ and $4+)$ because of the limited access to oxygen during the calcination process and the possible surface doping by indium and tin species. The modification of titania by ITO significantly increases the photoelectrochemical properties of the $\mathrm{TiO}_{2} \mathrm{NTs}$ layer as was revealed by linear voltammetry and chronoamperometry measurements performed during sample irradiation. The sample modified with only 5-nm ITO film exhibits the highest photocurrent enhancement factor that reaches 4.4 and 3.5 , when the sample is immersed in neutral and basic electrolyte, respectively, comparing to the pristine titania. Such improvement has not been reported yet for any other $\mathrm{TiO}_{2}$ structures doped with indium and tin or modified with their oxides. As it was discussed, we believe that improved photoactivity results mainly from the phenomena occurring at the $\mathrm{TiO}_{2} / \mathrm{SnO}_{2} /$ $\mathrm{In}_{2} \mathrm{O}_{3}$ interface: electronic structure modification and facilitated charge separation. Besides, $\mathrm{TiO}_{2}$ with 5 -nm sputtered ITO film exhibits the lowest resistance among other materials and excellent electrochemical stability during prolonged exposition to the solar radiation. Taking into account both observed photoactivity and photostability, proposed modification could be regarded as a promising method for further commercial fabrication of titania NTs-based photoanode.

Acknowledgements This work was financially supported by the Polish National Science Centre: Grant No. 2012/07/D/ST5/02269. Katarzyna Siuzdak was supported by the Foundation for Polish Science (FNP). Jacek Ryl gratefully acknowledges the financial support from Polish National Science Centre under Grant No. 2015/17/D/ ST5/02571. Mariusz Szkoda gratefully acknowledges the financial support from Polish National Science Centre under Grant No. 2016/23/N/ST5/02071. Authors are also thankful to $€$. Macewicz for help in the preliminary research works and PhD DSc Eng. M. Gazda, Professor of Gdańsk University of Technology, for the registration of XRD spectra.

\section{References}

[1] J.M. Macak, H. Tsuchiya, A. Ghicov, K. Yasuda, R. Hahn, S. Bauer, P. Schmuki, Curr. Opin. Solid State Mater. Sci. 11, 3 (2007)

[2] P. Roy, S. Berger, P. Schmuki, Angew. Chem. Int. Ed. 50, 2904 (2011)

[3] C. Chen, Y. Wei, G. Yuan, Q. Liu, R. Lu, X. Huang, Y. Cao, P. Zhu, Adv. Funct. Mater. 1701575, 1 (2017)

[4] L. Guo, K. Liang, K. Marcus, Z. Li, L. Zhou, P.D. Mani, H. Chen, C. Shen, Y. Dong, L. Zhai, K.R. Coffey, N. Orlovskaya, Y.H. Sohn, Y. Yang, A.C.S. Appl, Mater. Interfaces 8, 34970 (2016)

[5] L. Guo, Z. Li, K. Marcus, S. Navarro, K. Liang, L. Zhou, P.D. Mani, S.J. Florczyk, K.R. Coffey, N. Orlovskaya, Y.H. Sohn, Y. Yang, ACS Sens. 2, 621 (2017)

[6] C.Y. Lee, A.C. Taylor, S. Beirne, G.G. Wallace, Adv. Energy Mater. 1701060, 1 (2017)

[7] K. Siuzdak, M. Szkoda, M. Sawczak, A. Lisowska-Oleksiak, New J. Chem. 39, 2741 (2015)

[8] J.H. Lee, J. Il Youn, Y.J. Kim, H.J. Oh, J. Mater. Sci. Technol. 31, 664 (2015)

[9] K. Siuzdak, M. Szkoda, M. Sawczak, A. Lisowska-Oleksiak, J. Karczewski, J. Ryl, RSC Adv. 5, 50379 (2015)

[10] K. Siuzdak, M. Szkoda, A. Lisowska-Oleksiak, K. Grochowska, J. Karczewski, J. Ryl, Appl. Surf. Sci. 357, 942 (2015)

[11] R. Asapu, V.M. Palla, B. Wang, Z. Guo, R. Sadu, D.H. Chen, Journal Photochem. Photobiol. A Chem. 225, 81 (2011)

[12] H. Cao, Z. Fan, G. Hou, Y. Tang, G. Zheng, Electrochim. Acta 125, 275 (2014)

[13] D. Feng, Z. Rui, Y. Lu, H. Ji, Chem. Eng. J. 179, 363 (2012)

[14] F. Xiao, J. Phys. Chem. C 116, 16487 (2012)

[15] M. Wang, L. Sun, Z. Lin, J. Cai, K. Xie, C. Lin, Energy Environ. Sci. 6, 1211 (2013)

[16] Y. Yuan, Z. Ye, H. Lu, B. Hu, Y. Li, D. Chen, J. Zhong, Z. Yu, Z. Zou, ACS Catal. 6, 532 (2016)

[17] Y. Muramatsu, Q. Jin, M. Fujishima, H. Tada, Appl. Catal. B Environ. 119, 74 (2012)

[18] J. Jeong, B. Choe, J. Lee, J. Lee, J. Electr. Mater. 43, 11664 (2014)

[19] X. Xia, Z. Zeng, X. Li, Y. Zhang, J. Tu, N.C. Fan, H. Zhang, H.J. Fan, Nanoscale 5, 6040 (2013)

[20] M. Lübke, D. Howard, C.F. Armer, A.J. Gardecka, A. Lowe, M.V. Reddy, Z. Liu, J.A. Darr, Electrochim. Acta 231, 247 (2017)

[21] J. Li, X. Xu, X. Liu, C. Yu, D. Yan, Z. Sun, L. Pan, J. Alloys Compd. 679, 454 (2016)

[22] Y. Duan, N. Fu, Q. Liu, Y. Fang, X. Zhou, J. Zhang, Y. Lin, J. Phys. Chem. C 116, 8888 (2012)

[23] U.V. Desai, C. Xu, J. Wu, D. Gao, J. Phys. Chem. C 117, 3232 (2013)

[24] D.A. Zatsepin, D.W. Boukhvalov, E.Z. Kurmaev, I.S. Zhidkov, S.S. Kim, L. Cui, N.V. Gavrilov, S.O. Cholakh, I. During, Phys. Status Solidi B 252, 1890 (2015)

[25] I. Hanzu, T. Djenizian, G.F. Ortiz, P. Knauth, J. Phys. Chem. C 113, 20568 (2009)

[26] V. Amoli, M.G. Sibi, B. Banerjee, M. Anand, A. Maurya, S.A. Farooqui, A. Bhaumik, A.K. Sinha, A.C.S. Appl, Mater. Interfaces 7, 810 (2015)

[27] S.K. Poznyak, D.V. Talapin, A.I. Kulak, J. Phys. Chem. B 105, 4816 (2001)

[28] M. Barun, A. Mondal, B. Choudhuri, B. Kishore, S. Chakrabartty, C. Ngangbam, J. Alloys Compd. 615, 440 (2014)

[29] Y. Cao, T. He, Y. Chen, Y. Cao, J. Phys. Chem. C 114, 3627 (2010) 
[30] M. Xu, P. Da, H. Wu, D. Zhao, G. Zheng, Nano Lett. 12, 1503 (2012)

[31] M.V. Sheridan, D.J. Hill, B.D. Sherman, D. Wang, S.L. Marquard, K.R. Wee, J.F. Cahoon, T.J. Meyer, Nano Lett. 17, 2440 (2017)

[32] X. Li, H. Zhu, J. Wei, K. Wang, E. Xu, Z. Li, D. Wu, Appl. Phys. A Mater. Sci. Process. 97, 341 (2009)

[33] S.H. Kang, J. Kim, H.S. Kim, Y. Sung, J. Ind. Eng. Chem. 14, 52 (2008)

[34] D. Yan, C. Yu, Y. Bai, W. Zhang, T. Chen, B. Hu, Z. Sun, L. Pan, Chem. Commun. 51, 8261 (2015)

[35] E. Wang, W. Yang, Y. Cao, J. Phys. Chem. C 113, 20912 (2009)

[36] P. Song, X. Zhang, M. Sun, X. Cui, Y. Lin, Nanoscale 4, 1800 (2012)

[37] Y.K. Lai, J.Y. Huang, H.F. Zhang, V.P. Subramaniam, Y.X. Tang, D.G. Gong, L. Sundar, L. Sun, Z. Chen, C.J. Lin, J. Hazard. Mater. 184, 855 (2010)

[38] T. Sreethawong, S. Ngamsinlapasathian, S. Yoshikawa, J. Colloid Interface Sci. 421, 191 (2014)

[39] A. Thogersen, M. Rein, E. Monakhov, J. Mayandi, S. Diplas, J. Appl. Phys. 109, 113532 (2011)

[40] C. Donley, D. Dunphy, D. Paine, C. Carter, K. Nebesny, P. Lee, D. Alloway, N.R. Armstrong, Langmuir 18, 450 (2002)

[41] Q. Zhang, Y. Li, E.A. Ackerman, M. Gajdardziska-Josifovska, H. Li, Appl. Catal. A Gen. 400, 195 (2011)

[42] M. Boota, M. Pasini, F. Galeotti, W. Porzio, M. Zhao, J. Halim, Y. Gogotsi, Chem. Mater. 29, 2731 (2017)

[43] X. Zhou, B. Jin, S. Zhang, H. Wang, H. Yu, F. Peng, Electrochem. Commun. 19, 127 (2012)

[44] H. Li, J. Xing, Z. Xia, J. Chen, Electrochim. Acta 139, 331 (2014)
[45] J. Cho, F.S. Denes, R.B. Timmons, Chem. Mater. 18, 2989 (2006)

[46] M.Z. Ge, C.Y. Cao, J.Y. Huang, S.H. Li, S.N. Zhang, S. Deng, Q.S. Li, K.Q. Zhang, Y.K. Lai, Nanotechnol. Rev. 5, 75 (2016)

[47] Y. Li, G. Ma, S. Peng, G. Lu, S. Li, Appl. Surf. Sci. 254, 6831 (2008)

[48] J. Yang, H. Bai, Q. Jiang, J. Lian, Thin Solid Films 516, 1736 (2008)

[49] T.I.T. Okpalugo, P. Papakonstantinou, H. Murphy, J. Mclaughlin, N.M.D. Brown, Carbon 43, 153 (2005)

[50] E.A. Konstantinova, A.I. Kokorin, S. Sakthivel, Chimia. Int. J. Chem. 61, 810 (2007)

[51] M. Xing, F. Shen, B. Qiu, J. Zhang, Sci. Rep. 4, 6341 (2014)

[52] M. Senthilkumar, J. Mathiyarasu, J. Joseph, K.L.N. Phani, V. Yegnaraman, Mater. Chem. Phys. 108, 403 (2008)

[53] E. Thimsen, N. Rastgar, P. Biswas, J. Phys. Chem. C 112, 4134 (2008)

[54] S. Crawford, E. Thimsen, P. Biswas, J. Electrochem. Soc. 156, 346 (2009)

[55] J. Hu, Q. Liu, H. Zhang, C.D. Chen, Y. Liang, R.G. Du, C.J. Lin, J. Mater. Chem. A 3, 22605 (2015)

[56] B. Sun, T. Shi, Z. Peng, W. Sheng, T. Jiang, G. Liao, Nanoscale Res. Lett. 8, 462 (2013)

[57] V. Amoli, S. Bhat, A. Maurya, B. Banerjee, A. Bhaumik, A.K. Sinha, A.C.S. Appl, Mater. Interfaces 7, 26022 (2015)

[58] K. Trzciński, M. Szkoda, K. Siuzdak, M. Sawczak, A. LisowskaOleksiak, Electrochim. Acta 222, 421 (2016)

[59] Q. Jin, M. Fujishima, M. Nolan, A. Iwaszuk, H. Tada, J. Phys. Chem. C 116, 12621 (2012)

[60] T.Q. Nguyen, A.K. Thapa, V.K. Vendra, J.B. Jasinski, G.U. Sumanasekera, M.K. Sunkara, RSC Adv. 4, 3312 (2014) 